\title{
One-stage surgical management of an esophagopericardial fistula presenting with tamponade
}

\author{
Panos N. Vardas, MD, ${ }^{a}$ Matthew D. Acton, BS, ${ }^{a}$ Carlo Maria Rosati, MD, ${ }^{b}$ and Kenneth A. Kesler, MD, \\ Indianapolis, Ind
}
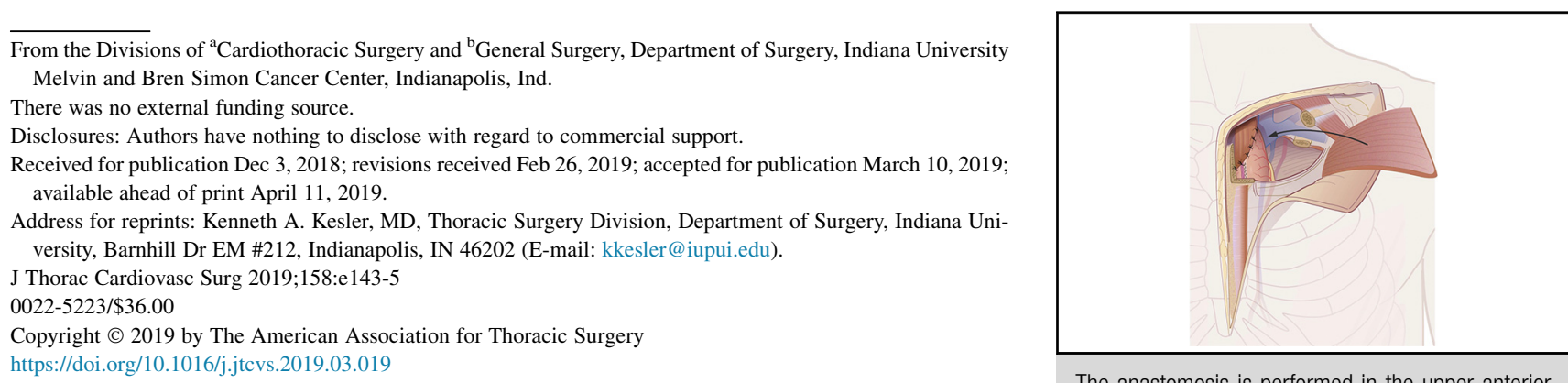

The anastomosis is performed in the upper anterior mediastinum and covered with a muscle.

Esophageal fistulas to the airway are rare and frequently fatal complications of chemoradiation therapy in the treatment of squamous cell cancers involving the middle to upper thoracic esophagus. We report a very rare case of a 35 -year-old man who presented in cardiogenic shock as a result of tamponade secondary to an esophagopericardial fistula after chemoradiation therapy for a squamous cell carcinoma originating in the distal esophagus. Initial treatment included emergency pericardiocentesis. After clinical improvement, a total esophagectomy with immediate reconstruction was performed, routing a stomach conduit through the anterior mediastinum.

\section{CLINICAL SUMMARY}

A 35-year-old man presented with progressive dysphagia and an associated 40-pound weight loss secondary to biopsy-proven, well-differentiated squamous cell carcinoma in the distal esophagus at $35 \mathrm{~cm}$ from the incisors. Previous medical history was significant for type 2 diabetes. He reported a 10-pack-year smoking history and denied ethanol abuse. Clinical staging included computed tomography-positron emission tomography fusion imaging and endoscopic ultrasonography, which demonstrated a cT3NOM0 neoplasm. The patient received neoadjuvant chemoradiation therapy with a carboplatin-paclitaxel and 41.4-Gy radiation regimen, with radiation fields set approximately $5 \mathrm{~cm}$ beyond the gross tumor volume cranially and caudally and $2 \mathrm{~cm}$ in lateral and anteroposterior borders, in accordance with CROSS protocol. ${ }^{1}$ The patient had a good clinical response according to repeated computed tomographic imaging. He was scheduled for elective Ivor Lewis esophagectomy 6 weeks after completion of therapy. Three days before scheduled surgery, the patient had rather acute onset of chest pain, dyspnea, and lethargy. He presented to a local emergency department with severe hypotension, tachycardia, and acidosis (base deficit $-14 \mathrm{mEq} / \mathrm{L}$ ). The patient was intubated on an emergency basis, and vasoactive agents and antibiotics were administered. Chest computed tomography was suggestive of a large pericardial effusion and a distal esophageal perforation (Figure 1). He was rapidly transferred to our institution, where a transthoracic echocardiogram confirmed a hemodynamically significant pericardial effusion and an emergency ultrasound-guided pericardiocentesis, which yielded $650 \mathrm{~mL}$ of purulent material, resulted in hemodynamic stability. Subsequent pericardial fluid cytologic examination, however, was negative for malignant cells and showed no bacterial or fungal growth. A contrast esophagogram confirmed a distal esophageal perforation in the location of the treated neoplasm, with a $1-\mathrm{cm}$ wide fistulous tract extending anteriorly into the middle mediastinum. The patient required kidney replacement therapy but was otherwise clinically stabilized 4 days later and was determined to be a candidate for what was thought to be palliative surgical management for a malignant fistula with pericardial sac involvement.

A right thoracotomy through the 6th intercostal space was initially performed for decortication of a basilar empyema, mediastinal débridement, and pericardial irrigation. The gastric cardia was divided just below the gastroesophageal junction with a stapler and the esophagus, fistula tract, and involved pericardium with surrounding lymph nodes were mobilized into the thoracic inlet. The thoracotomy 


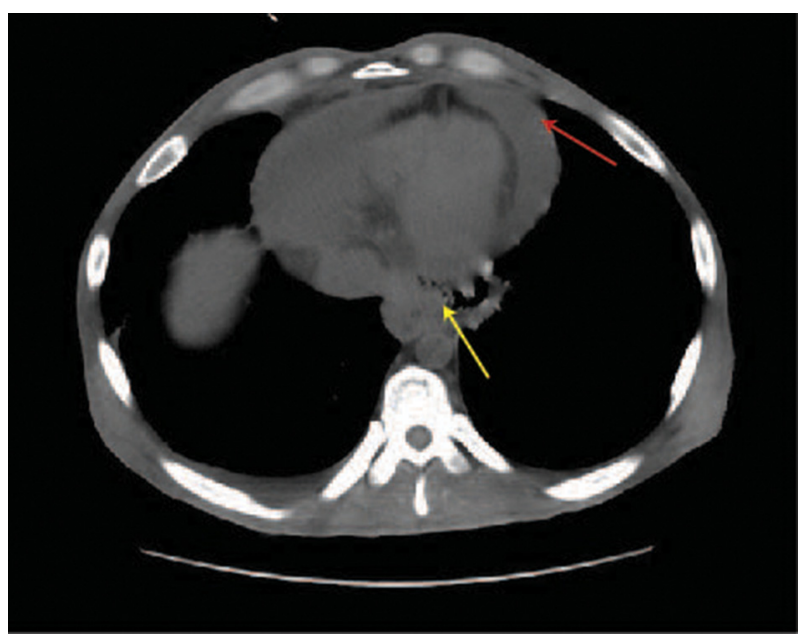

FIGURE 1. Representative computed tomographic image that shows significant pericardial effusion (red arrow) and distal esophageal wall and mediastinal air (yellow arrow), suggestive of esophageal perforation.

incision was closed after pericardial and mediastinal drains were placed. As the patient remained in stable condition, it was determined that immediate reconstruction, as opposed to excision and cervical esophageal diversion, should be considered for optimal palliation. The patient was placed in supine position, and an upper midline laparotomy performed. A celiac lymph node dissection was accomplished, and a gastric conduit was constructed, including a HeinekeMikulicz pyloroplasty. The diaphragmatic crus was closed with a bioprosthetic mesh because of a relatively large crural defect in an infected field, and a feeding jejunostomy tube was placed. The leftward sternoclavicular joint was excised. The stomach conduit was advanced through the anterior mediastinum, avoiding the bacterial contamination and possible malignant seeding of the posterior mediastinum. A side-to-side cervical esophagogastric anastomosis was established and covered with an ipsilateral pectoralis major rotational flap (Figure 2). ${ }^{2}$ The patient's postoperative course was uneventful and included resolution of renal failure. Pleural and pericardial drains were removed after negligible drainage, 2 and 3 weeks after surgery, respectively. Antibiotics were discontinued after 10 days. The patient was discharged in good condition tolerating an oral diet on the 32nd postoperative day. Gratifyingly, the final pathologic examination demonstrated a complete pathologic response without evidence of residual neoplasm in the esophagus and 10 lymph nodes sampled. The patient has continued to do well and remains free of disease 3 years after surgery.

\section{DISCUSSION}

Esophagopericardial fistulas are very rare and typically fatal complications of benign or malignant esophageal diseases. Although very rare, a fistula to the pericardium

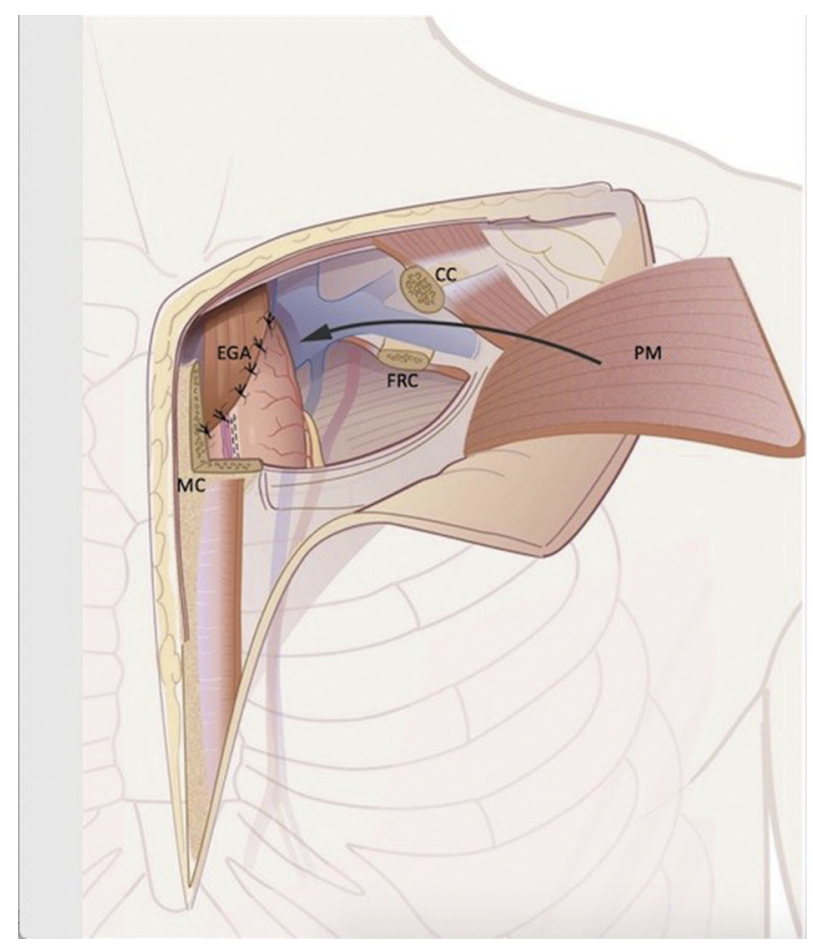

FIGURE 2. Representative image of the esophagogastric anastomosis $(E G A)$ at the thoracic inlet. Under the left sternoclavicular joint, the esophagogastric anastomosis was performed in a side-to-side fashion. The anastomosis was covered with a pectoralis rotational flap (black arrow) to help contain any potential anastomotic leak, as well as to buttress the bony thoracic inlet defect. $C C$, Clavicular cut; $F R C$, first rib cut; $P M$, pectoralis major muscle; $M C$, manubrial cut.

secondary to an esophageal malignancy is arguably more amenable to either curative or palliative surgery, however, than fistulas to airway or aorta. Similar to pathophysiology of the more common esophageal airway fistulas, neoadjuvant chemoradiation increases the risk of esophagopericardial fistula formation. ${ }^{3}$

The standard surgical option for a perforated esophageal carcinoma would be esophagectomy with establishment of an end-esophageal fistula and consideration of delayed reconstruction. This approach, although potentially lifesaving, obviously leaves patients with poor quality of life for a predictable short life expectancy. The unusual patient who does recover from such an operation then faces a second major reconstructive surgical procedure. Alternatively, endoscopically placed self-expanding stents have been described for management of benign and malignant esophageal perforations, including fistulas into adjacent organs (Table 1). Consideration could have been given to a temporizing stent before surgery; however, complete pericardial drainage and mediastinal débridement was deemed to be needed. There has been some success with use of esophageal stent placement and pericardial drainage in benign esophagopericardial fistula secondary to ablation for atrial 
TABLE 1. Reported cases of esophagopericardial fistula secondary to esophageal malignancy

\begin{tabular}{|c|c|c|c|c|}
\hline Report & Etiology & Presentation & Management & Outcome \\
\hline Wang $^{4}$ & Squamous cell carcinoma & Cardiac tamponade & $\begin{array}{l}\text { Percutaneous pericardial } \\
\text { drainage }\end{array}$ & $\begin{array}{l}\text { Discharge from hospital, } \\
\text { unknown follow-up }\end{array}$ \\
\hline Takayama $^{5}$ & Squamous cell carcinoma & Purulent pericarditis & Pericardial drainage & Died (6 wk) \\
\hline Cheng $^{6}$ & $\begin{array}{l}\text { Esophageal carcinoma } \\
\quad \text { (unknown type) }\end{array}$ & Pyopneumopericardium & Pericardial drainage & Died (10 d) \\
\hline Dafnios $^{7}$ & $\begin{array}{l}\text { Adenocarcinoma of the } \\
\text { esophagogastric junction }\end{array}$ & $\begin{array}{l}\text { Pneumopericardium, } \\
\text { pleural effusion }\end{array}$ & $\begin{array}{l}\text { Pericardial drainage, } \\
\text { pleurodesis }\end{array}$ & Died (5 wk) \\
\hline Wlodarczyk $^{8}$ & $\begin{array}{l}\text { Esophageal carcinoma } \\
\quad \text { (unknown type) }\end{array}$ & Cardiac tamponade & $\begin{array}{l}\text { Pericardial drainage, } \\
\text { esophageal stent }\end{array}$ & Died (7 mo) \\
\hline Tombazzi $^{9}$ & Squamous cell carcinoma & Cardiac tamponade & Esophageal stent & Died (5 wk) \\
\hline Peyrin-Biroulet $^{10}$ & Squamous cell carcinoma & Purulent pericarditis & Pericardial drainage & Died $(<24$ h) \\
\hline Wiedmann $^{11}$ & $\begin{array}{l}\text { Esophageal carcinoma } \\
\quad \text { (unknown type) }\end{array}$ & $\begin{array}{l}\text { Purulent pericarditis and } \\
\text { bilateral pleural effusion }\end{array}$ & Esophageal stent & Died (3 mo) \\
\hline Kaufman $^{12}$ & $\begin{array}{l}\text { Esophageal carcinoma } \\
\quad \text { (unknown type) }\end{array}$ & Cardiac tamponade & $\begin{array}{l}\text { Pericardial drainage, patient } \\
\text { refused esophageal stent }\end{array}$ & $\operatorname{Died}(7 \mathrm{~d})$ \\
\hline Nakshabendi ${ }^{13}$ & Adenocarcinoma & Pyopneumopericardium & Esophageal stent & Died (2 wk) \\
\hline $\mathrm{Kohl}^{14}$ & Squamous cell carcinoma & Pericardial effusion & Esophageal stent & Died (6 wk) \\
\hline Tukkie $^{15}$ & Adenocarcinoma & Hydropneumopericardium & Esophageal stent & $\begin{array}{l}\text { Discharge from hospital, } \\
\text { unknown follow-up }\end{array}$ \\
\hline Welch $^{16}$ & Squamous cell carcinoma & Purulent pericarditis & $\begin{array}{l}\text { Pericardial drainage, } \\
\text { cervical esophagostomy }\end{array}$ & Died (20 d) \\
\hline
\end{tabular}

fibrillation. ${ }^{17}$ Among all patients reported to have undergone stent placement for malignant esophagopericardial fistulas, with or without pericardial drainage to date, however, there have been no long-term survivors, with most dying within a few weeks of intervention. ${ }^{7,15}$ In light of the patient's age, clinical stability, and satisfactory mediastinal débridement, we elected to perform an esophagogastrectomy with immediate reconstruction with a gastric conduit routed through the uncontaminated anterior mediastinum, allowing resumption of an oral diet and sparing a second reconstructive operation. We believe that a similar surgical approach could be used for patients with localized malignant esophageal perforations without fistulization into adjacent organs.

\section{References}

1. Shapiro J, van Lanschot JJ, Hulshof MC, van Hagen $P$, van Berge Henegouwen MI, Wijnhoven BP, et al; CROSS study group. Neoadjuvant chemoradiotherapy plus surgery versus surgery alone for oesophageal or junctional cancer (CROSS): long-term results of a randomized controlled trial. Lancet Oncol. 2015;16:1090-8.

2. Kesler KA, Ramchandani NK, Jalal SI, Stokes SM, Mankins MR, Ceppa DP, et al. Outcomes of a novel intrathoracic esophagogastric anastomotic technique. J Thorac Cardiovasc Surg. 2018;156:1739-45.

3. Tsushima T, Mizusawa J, Sudo K, Honma Y, Kato K, Igaki H, et al; Japan Esophageal Oncology Group of Japan Clinical Oncology Group (JCOG). Risk factors for esophageal fistula associated with chemoradiotherapy for locally advanced unresectable esophageal cancer: a supplementary analysis of JCOG0303. Medicine (Baltimore). 2016;95:e3699.

4. Wang MC, Huang BH, Kok VC. Esophagopericardial fistula and purulent pericarditis causing cardiac tamponade during concurrent chemoradiotherapy for esophageal cancer: a case report. Therapeut Radiol Oncol. 2017;24: 67-75.

5. Takayama T, Okura Y, Funakoshi K, Sato T, Ohi H, Kato T. Esophageal cancer with an esophagopericardial fistula and purulent pericarditis. Intern Med. 2013;52:243-7.

6. Cheng YT, Chong KC, Tsai MJ. Esophagopericardial fistula with pyopneumopericardium secondary to esophageal carcinoma. Intern Med. 2011;50:2681.

7. Dafnios N, Anastasopoulos G, Marinis A, Polydorou A, Gkiokas G, Fragulidis G, et al. Esophagopericardial fistula as a rare complication after total gastrectomy for cancer. World J Surg Oncol. 2009; 7:58.

8. Włodarczyk J, Olechnowicz H, Kocoń P. Esophago-pericardial fistula during the course of primary esophageal carcinoma. Ann Thorac Surg. 2008;86:1967-9.

9. Tombazzi C, Marino G, Yong J, Vallejo V, Reddy K. Malignant esophageal pericardial fistula presenting as cardiac tamponade. Dig Dis Sci. 2006;51:1290-3.

10. Peyrin-Biroulet L, Bronowicki JP, Bigard MA, Regent D, Walter S, Platini C Contribution of computed tomography with oral media contrast to the diagnosis of esophago-pericardial fistula. Clin Imaging. 2006;30:347-9.

11. Wiedmann M, Hagendorff A, Bohm R, Schulz T, Mossner J, Caca K. Malignant oesophago-pleuro-pericardial fistula in a patient with oesophageal carcinoma. Z Kardiol. 2005;94:411-4.

12. Kaufman J, Thongsuwan N, Stern E, Karmy-Jones R. Esophageal-pericardial fistula with purulent pericarditis secondary to esophageal carcinoma presenting with tamponade. Ann Thorac Surg. 2003;75:288-9.

13. Nakshabendi I, Havaldar S, Nord H. Pyopneumopericardium due to an esophagopericardial fistula: treatment with a coated expandable metal stent. Gastrointest Endosc. 2000;52:689-91.

14. Kohl O, Schäffer R, Doppl W. Purulent pericarditis as an initial manifestation of esophageal carcinoma. Dtsch Med Wochenschr. 1999;124:381-5.

15. Tukkie R, Hulst RWM, Sprangers F, Bartelsman JF. An esophagopericardial fistula successfully treated with an expandable covered metal mesh stent. Gastrointest Endosc. 1996;43:165-7.

16. Welch TG, White TR, Lewis RP, Altieri Pl, Vasko JS, Kilman JW. Esophagopericardial fistula presenting as cardiac tamponade. Chest. 1972;62:728-31.

17. Quénéhervé L, Musquer N, Léauté F, Coron E. Endoscopic management of an esophagopericardial fistula after radiofrequency ablation for atrial fibrillation. World J Gastroenterol. 2013;19:3352-3. 